\title{
The carboxyl-terminus of eremomycin facilitates binding to the non-D-Ala-D-Ala segment of the peptidoglycan pentapeptide stem
}

\author{
James Chang ${ }^{\S}$, Hongyu Zhou ${ }^{\ddagger}$, Maria Preobrazhenskaya ${ }^{\dagger}$, Peng Tao ${ }^{\ddagger}$, and Sung Joon \\ $\operatorname{Kim}^{\S, *}$ \\ §Department of Chemistry and Biochemistry, Baylor University, Waco, TX 76706 \\ ¥Department of Chemistry, Center for Drug Discovery, Design, and Delivery (CD4), Center for \\ Scientific Computation, Southern Methodist University, Dallas, TX 7 5275, USA \\ †Gause Institute of New Antibiotics, Moscow, Russian Federation
}

\begin{abstract}
Glycopeptide antibiotics inhibit cell wall biosynthesis in Gram-positive bacteria by targeting the peptidoglycan (PG) pentapeptide stem structure (L-Ala-D-iso-Gln-L-Lys-D-Ala-D-Ala). Structures of glycopeptide complexed with PG-stem mimic have shown that the D-Ala-D-Ala is the primary drug-binding site; however, biochemical evidences suggest that the glycopeptide-PG interaction involves more than D-Ala-D-Ala binding. Glycopeptide interactions with the non-DAla-D-Ala segment of the PG stem were investigated using solid-state NMR. LCTA-1421, a double ${ }^{15} \mathrm{~N}$-enriched eremomycin derivative with a C-terminus ${ }^{15} \mathrm{~N}$-amide and ${ }^{15} \mathrm{~N}$-Asn amide, was complexed with whole cells of Staphylococcus aureus grown in a defined media containing L$\left[3-{ }^{13} \mathrm{C}\right]$ Ala and D-[1- $\left.{ }^{13} \mathrm{C}\right] \mathrm{Ala}$ in the presence of alanine racemase inhibitor alaphosphin. ${ }^{13} \mathrm{C}\left\{{ }^{15} \mathrm{~N}\right\}$ and ${ }^{15} \mathrm{~N}\left\{{ }^{13} \mathrm{C}\right\}$ rotational-echo double resonance (REDOR) NMR measurements determined the ${ }^{13} \mathrm{C}-{ }^{15} \mathrm{~N}$ internuclear distances between the ${ }^{15} \mathrm{~N}$-Asn amide of LCTA-1421 and the ${ }^{13} \mathrm{Cs}$ of the bound D-[1-13 C]Ala-D-[1- $\left.{ }^{13} \mathrm{C}\right]$ Ala to 5.1 and $4.8 \AA$, respectively. These measurements also determined the distance from the C-terminus ${ }^{15} \mathrm{~N}$-amide of LCTA-1421 to the L-[3- $\left.{ }^{13} \mathrm{C}\right] \mathrm{Ala}$ of PG to $3.5 \AA$. The measured REDOR distance constraints position the glycopeptide $\mathrm{C}$-terminus in proximity to the L-Ala of the PG, suggesting that the C-terminus of glycopeptide interacts near the L-Ala segment of the PG stem. In vivo REDOR measurements provided structural insight into how C-terminus modified glycopeptide antibiotics operate.
\end{abstract}

\section{Graphical Abstract}

\footnotetext{
*Corresponding Author: Sung Joon Kim, Sung_J_Kim@baylor.edu.

Supplemental Information

Chemical structure of classes of glycopeptide antibiotics, a summary table of ${ }^{13} \mathrm{C}-15_{\mathrm{N}}$ REDOR distance constraints determined for LCTA-1421bound to peptidoglycan in intact whole-cells of $S$. aureus, and minimal inhibitory concentrations of C-terminus modified glycopeptide antibiotics against vancomycin susceptible and resistant pathogens are provided.
} 


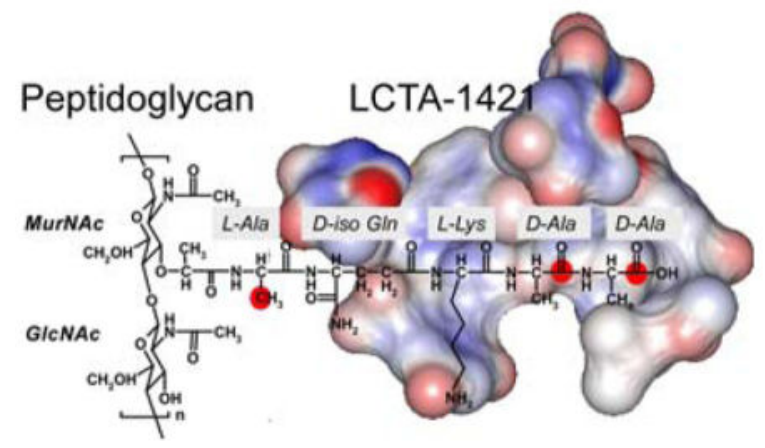

\section{Keywords}

Eremomycin; glycopeptide; REDOR; $S$. aureus; solid-state NMR

Vancomycin is a glycopeptide antibiotic exhibiting potent activities against almost all strains of Gram-positive cocci and bacilli. ${ }^{1}$ In 1956, Eli Lilly and Company discovered vancomycin in soil samples collected from Borneo; the antibiotic was being produced by soil microbe Amycolatopsis orientalis. Since the discovery of vancomycin, researchers have identified about 50 different glycopeptide-antibiotic producing organisms with over one hundred different natural glycopeptides. ${ }^{2,3}$ All glycopeptides have a heptapeptide core (aglycon) structure formed by heavily cross linked amino acids through a series of phenolic oxidative couplings. The glycopeptides are classified into four types based on their chemical structure (Supplemental Figure S1). ${ }^{4}$ Vancomycin is a Type I glycopeptide with methylated-leucine and asparagine at the first and third positions of the aglycon, respectively. In Type II glycopeptides, such as avoparcin, the first and the third residues are replaced by aromatic amino acids. Type III and IV glycopeptides also have aromatic amino acids at the first and third positions, but they are cross-linked by a phenolic-ether linkage. Ristocetin is an example of Type III, with its aglycon structured modified by six sugar adducts. Teicoplanin, a Type IV glycopeptide, has an aglycon-core structure identical to Type III, but differs by an acyl chain attached to the sugar moiety.

Glycopeptides inhibit peptidoglycan (PG) biosynthesis by binding to lipid II, a membranebound PG precursor. This behavior was discovered when adding vancomycin to cell extracts of $S$. aureus inhibited the formation of the PG (Figure 1) and the incorporation of glycine into the lipid II. ${ }^{5}$ When vancomycin is added to whole cells of bacteria, cytoplasmic precursors accumulate (Park's Nucleotide) and the cell wall thins. These results support the hypothesis that vancomycin inhibits transglycosylation by targeting the lipid II. ${ }^{6}$ By binding to lipid II, vancomycin effectively sequesters the lipid transporter $\mathrm{C}_{55}$, the limiting factor in PG biosynthesis, which is present only in a small number of copies per bacterium. The lipid transporter is only regenerated from lipid II during the transglycosylation step of PG biosynthesis.

Vancomycin binding to D-Ala-D-Ala was first determined when vancomycin failed to inhibit in vitro PG polymerization of UDP-MurNac-tetrapeptide purified from the membrane fractions of Gaffkya homari. ${ }^{7}$ Since the UDP-MurNac-tetrapeptide lacked the terminal D- 
Ala found on the PG-pentapeptide stem (Figure 1), it was inferred that vancomycin operates in part by binding to the terminal D-Ala-D-Ala of PG. When adding D-Ala-D-Ala dipeptide antagonized vancomycin's activities, this finding confirmed that the D-Ala-D-Ala of PG is the vancomycin binding site. Vancomycin dissociation constant to Acyl-D-Ala-D-Ala, determined by capillary electrophoresis, is $4.3 \mu \mathrm{M} .^{8}$

Figure 2 shows the $\mathrm{x}$-ray crystal structure of vancomycin bound to diacetyl-L-Lys-D-Ala-D$\mathrm{Ala}^{9}$ and the solution-state NMR structure of chloroeremomycin complexed with PG precursor analogue L-Ala-D-iso-Glu-L-Lys-D-Ala-D-Ala. ${ }^{10}$ Both vancomycin and chloroeremomycin share an identical heptapeptide core structure that forms the D-Ala-DAla binding site. Five hydrogen bonds stabilize the D-Ala-D-Ala as it is attached to the aglycon structure (Figure 2, bottom): i) the first three H-bonds are located between the amide-protons (NH2, NH3, NH4) and the carboxyl oxygen on the C-terminus of the D-AlaD-Ala, ii) a fourth bond is located between the carbonyl oxygen on the $4^{\text {th }}$ residue of the aglycon (CO4) and an amide proton of the terminal D-Ala, and iii) a fifth bond is located between the amide proton of the $7^{\text {th }}$ residue of the aglycon (NH7) and the carbonyl oxygen of the L-Lys. The hydrophobic interactions between the aromatic residues of the glycopeptide core structure and the methyl group of the alanines in the dipeptide is thought to further stabilize the drug-bound structure. In both x-ray crystal and solution-state NMR structures, the disaccharides of vancomycin and chloroeremomycin do not participate in DAla-D-Ala binding.

Structure and activity studies of glycopeptides and biochemical evidences suggest that in vivo glycopeptide-PG binding is far more complex than mere D-Ala-D-Ala dipeptide binding. ${ }^{2,11}$ Some of the evidences are listed. 1) The strength of the glycopeptide's binding affinity to D-Ala-D-Ala does not correlate with the drug's activity. For example, the binding affinity between chloroeremomycin and diacetyl-L-Lys-D-Ala-D-Ala is approximately 23 times less than vancomycin, but its activity is approximately 5 to 10 times greater. 2) The chlorine atom on the second amino acid of vancomycin improves the activity. The dechlorinated vancomycin (monodechlorovancomycin) is only half as active as vancomycin. 3) The removal of sugars from vancomcyin (deglycosylated vancomycin) does not affect the D-Ala-D-Ala binding, but it reduces the activity by a factor of 5 . The sugars on vancomycin have been attributed to the formation of drug dimer, but in vivo glycopeptides are found as monomers, ${ }^{12-16}$ which suggests that the sugars enhance the activity by facilitating the PG binding through sugar-PG interactions. ${ }^{15}$ 4) Methylated leucine, the first amino acid on vancomycin, is crucial for activity. The Edman degradation removal of leucine destroys the dipeptide binding affinity and its activity. 5) Asparagine, the third residue of vancomycin, does not participate in D-Ala-D-Ala binding but is required for its activity. ${ }^{17}$ Replacing asparagine with glutamine (lengthening the side chain by 1 carbon) or replacing it with an aspartate (introducing negative charge) reduces the activity by 2 and 10 times, respectively. Asparagin substitution by isoasparte destroys the antimicrobial activity. ${ }^{2,11} 6$ ) Alkylation of the drug sugar by a hydrophobic side chain improves the activity. ${ }^{18-21} 7$ ) The carboxyl terminus modifications of the glycopeptide improve the activity even though it is not involved in the D-Ala-D-Ala binding. ${ }^{22}$ 
In this study, we investigate in vivo glycopeptide-PG binding interactions using solid-state NMR. Unlike solution-state NMR and x-ray diffraction structures based on the drug bound to PG-mimicking peptides, solid-state NMR enables direct investigation of glycopeptide-PG complex in intact whole cells of $S$. aureus. In order to probe the glycopeptide-PG interactions, we have synthesized eremomycin derivative LCTA-1421 (Figure 3, top). LCTA-1421 is a bis $\left[{ }^{15} \mathrm{~N}\right]$ amide-carboxyeremomycin with two ${ }^{15} \mathrm{~N}$-isotope labeled probes: 1) a ${ }^{15} \mathrm{~N}$-amide at asparagine side chain of aglycon structure positioned inside the D-Ala-DAla binding pocket, and 2) a C-terminus ${ }^{15} \mathrm{~N}$-amide at the amino acid $7^{\text {th }}$ position.

The first probe, ${ }^{15} \mathrm{~N}$-amide asparagine of LCTA-1421, was used to characterize the structure of LCTA-1421 aglycon bound to the D-Ala-D-Ala segment of PG-stem in whole cells. We anticipated that the in situ aglycon structure of LCTA-1421 bound to the D-Ala-D-Ala segment of PG in cell wall will be different from the solution-state NMR and x-ray diffraction structures based on drug bound to a model peptide which suffers from the artifacts of drug dimerization and crystal lattice constraints, respectively. The in situ aglycon structure of LCTA-1421 bound to PG was inferred from the internuclear ${ }^{13} \mathrm{C}-{ }^{15} \mathrm{~N}$ distance measurements between the Asn ${ }^{15} \mathrm{~N}$-amide of LCTA-1421 to the ${ }^{13} \mathrm{Cs}$ in D-[1- $\left.{ }^{13} \mathrm{C}\right] \mathrm{Ala}-\mathrm{D}-$ $\left[1-{ }^{13} \mathrm{C}\right]$ Ala of PG-stem using rotational-echo double resonance (REDOR) NMR. ${ }^{23}, 24$

The second probe, the C-terminus ${ }^{15} \mathrm{~N}$-amide of LCTA-1421, was used to determine whether glycopeptide interaction with the non-D-Ala-D-Ala segment of PG-stem structure by measuring the ${ }^{13} \mathrm{C}-{ }^{15} \mathrm{~N}$ distances between the C-terminus ${ }^{15} \mathrm{~N}$-amide of LCTA-1421 to the ${ }^{13} \mathrm{C}$ in L-[3- $\left.{ }^{13} \mathrm{C}\right] \mathrm{Ala}$ of PG-stem. LCTA-1421 exhibits improved antimicrobial activity over parent compound (Supplementary Table S2) which suggests that the C-terminus ${ }^{15} \mathrm{~N}$-amide of LCTA-1421 interaction with the non-D-Ala-D-Ala segment of PG-stem is important for enhancing antimicrobial activity. Thus further understanding of glycopeptide interactions with non-D-Ala-D-Ala segment of PG-stem is crucial for the future for development of novel therapeutic agents, in particular against the vancomycin-resistant enterococci whose mechanism of vancomycin resistance is based on PG-stem D-Ala-D-Ala modification to DAla-D-Lac.

\section{MATERIAL AND METHODS}

\section{Synthesis of LCTA-1421 and LCTA-1110}

The synthesis of bis $\left[{ }^{15} \mathrm{~N}\right]$ amide-carboxyeremomycin (LCTA-1421) is described in Solov'eva et al. ${ }^{25}$ Briefly, eremomycin was treated with barium hydroxide at $37^{\circ} \mathrm{C}$ for $4 \mathrm{hr}$ to yield carboxyeremomycin. ${ }^{17}$ The $\left[{ }^{15} \mathrm{~N}\right]$ ammonium chloride was used to incorporate ${ }^{15} \mathrm{~N}$-enriched labels at the amino acid positions 3 and 7 of carboxyeremomycin using PyBOP and HBPyU as condensing reagents. ${ }^{25}$ The MS-ESI calculated mass for LCTA-1421 $\left(\mathrm{C}_{73} \mathrm{H}_{90} \mathrm{~N}_{9}{ }^{15} \mathrm{~N}_{2} \mathrm{O}_{25} \mathrm{Cl}\right)[\mathrm{M}+\mathrm{H}]^{+}$was 1557.57 , and the found $[\mathrm{M}+2 \mathrm{H}]^{2+}$ mass was 779.80 . The chemical shift of the ${ }^{15} \mathrm{~N}$-amide at the C-terminus (amino acid position 7) was 110.22 ppm, and the ${ }^{15} \mathrm{~N}$-amide side chain of asparagine (amino acid position 3) was $113.28 \mathrm{ppm}$ by solution-state NMR. The synthesis of eremomycin $p$-fluorophenylpiperazinamide (LCTA-1110) is described elsewhere, ${ }^{26}$ but briefly, LCTA-1110 was obtained by condensation of eremomycin with 4-fluorophenylpiperazine using PyBOP or HBPyU as condensing reagents. 


\section{Minimum inhibitory concentrations of glycopeptide antibiotics}

As recommended by the National Committee for Clinical Laboratory Standards, the micro dilution method using Mueller-Hinton broth determined minimal inhibitory concentrations (MICs) for vancomycin, eremomycin, LCTA-1421, and LCTA-1110 against Staphylococcus epidermidis, Staphylococcus haemolyticus, vancomycin-intermediate resistant $S$. aureus (VISA), vancomycin-susceptible Enterococcus faecium, vancomycin-susceptible Enterococcus faecalis, vancomycin-resistant E. faecium (VanA type), and vancomycinresistant E. faecalis (VanA type).

\section{Growth of whole cells of S. aureus}

A starter culture of $S$. aureus (ATCC 6538P) was added (1\% final volume) to a one-liter flask containing $250 \mathrm{~mL}$ of sterile $S$. aureus Standard Medium (SASM), which is composed of L-[3- $\left.{ }^{13} \mathrm{C}\right] \mathrm{Ala}$ and $\mathrm{D}-\left[1-{ }^{13} \mathrm{C}\right] \mathrm{Ala}$ in the presence of the alanine racemase inhibitor alaphosphin $(5 \mathrm{mg} / \mathrm{l})$. The detailed protocol for preparing SASM is described elsewhere. 15, 16, 27 The cells were harvested at the optical density of $660 \mathrm{~nm}$ of 1.0, washed twice, and then resuspended in $10 \mathrm{~mL}$ of water containing $7.1 \mathrm{mg}$ LCTA-1421. After $10 \mathrm{~min}$ on ice, the LCTA-1421-bacteria complex was frozen using liquid $\mathrm{N}_{2}$, and then lyophilized. The lyophilized sample weight was $250 \mathrm{mg}$.

\section{Solid-state NMR spectrometer and REDOR NMR parameters}

REDOR NMR experiments were performed on 89-mm bore Oxford (Cambridge, England) superconducting solenoid at $4.7 \mathrm{~T}(200 \mathrm{MHz}$ for $1 \mathrm{H})$, using a four-frequency transmissionline probe with a Chemagnetics/Varian ceramic stator. The samples were contained in 7.5$\mathrm{mm}$ outside diameter zirconia rotor spinning at $5 \mathrm{kHz}$ at room temperature. Radio frequency pulses for ${ }^{13} \mathrm{C}$ and ${ }^{15} \mathrm{~N}$ were produced by 1-kW ENI (Andover, MA) LPI-10 power amplifiers. Radio frequency pulses for ${ }^{1} \mathrm{H}$ were produced by a 1-kW Kalmus Engineering Int. Ltd (Valencia, CA) power amplifier, and the ${ }^{19} \mathrm{~F}$ pulses by a 1-kW Dressler Hochfrequenztechnik Gmbh (Stolberg-Vicht, Germany) power amplifier. All four amplifiers were under active control. Radio-frequency pulse lengths for $\pi$-pulse were $10 \mu$ s for ${ }^{13} \mathrm{C}$, ${ }^{15} \mathrm{~N}$ and ${ }^{19} \mathrm{~F}$. Proton-carbon and proton-nitrogen matched cross-polarization transfers were at $50 \mathrm{kHz}$ for $2 \mathrm{~ms}$. Proton dipolar decoupling during signal acquisition was $105 \mathrm{kHz}$. Standard XY-8 phase cycling ${ }^{28}$ was used for all refocusing and dephasing pulses.

REDOR NMR method recouples heteronuclear dipolar interactions under magic-angle spinning (MAS) $)^{23,24}$ to determine heteronuclear dipolar couplings and hence inter-nuclear distances. REDOR NMR is described elsewhere; $15,16,27$ briefly, in the full echo $\left(S_{0}\right)$ spectrum, dipolar dephasing is refocused over a single rotor period by MAS. In the $S$ spectrum, the spin part of the dipolar interaction prevented full refocusing by applying dephasing $\pi$-pulses, which reduced peak intensity for dipolar coupled spin pairs. The difference in signal intensity $\left(\Delta S=S_{0}-S\right)$ for the observed spin $\left({ }^{13} \mathrm{C}\right.$ or $\left.{ }^{15} \mathrm{~N}\right)$ is directly related to the heteronuclear dipolar coupling from which the corresponding distance to the dephasing spin is determined. The normalized REDOR difference $\left(\Delta S / S_{0}\right)$, based on the peak height measurements, is a direct measure of dipolar coupling, which was calculated using the modified Bessel function expressions given by Mueller et al. ${ }^{29}$ and de la Caillerie and Fretigny ${ }^{30}$ for an IS spin- $-1 / 2$ pair. The error bar for each REDOR dephasing was 
determined based on the maximum noise peak intensity respect to the dephased peak intensity.

\section{Molecular dynamics Simulation of PG-LCTA-1421 complex}

Molecular dynamic simulation of LCTA-1421 bound to PG pentapeptide stem structure was carried out without water molecules to focus on the drug-target binding interactions. The initial model was generated based on the NMR structure of chloroeremomycin complexed to the PG-stem structure (L-Ala-D-iso-Gln-L-Lys-D-Ala-D-Ala) (PDB ID: 1GAC). The CHARMM General Force Field $(\mathrm{CGenFF})^{31}$ for the simulating system was generated using the online server ParamChem (https://cgenff.paramchem.org/). After 20 ns molecular dynamics simulation, the following distance constraints were applied: i) 3.5 A between L[3- $\left.{ }^{13} \mathrm{C}\right]$ Ala with an ${ }^{15} \mathrm{~N}$-amide in C-terminus of LCTA-1421, ii) $5.1 \AA$ between $\mathrm{D}\left[1-{ }^{13} \mathrm{C}\right]$ Ala with ${ }^{15} \mathrm{~N}$-amide asparagine in LCTA-1421, and iii) $4.8 \AA$ between $\mathrm{D}\left[1-{ }^{13} \mathrm{C}\right] \mathrm{Ala}$ with the ${ }^{15} \mathrm{~N}$-amide at the C-terminus of LCTA-1421. Additional harmonic constraints (5 $\mathrm{kcal} / \mathrm{mol}$ ) were added to prevent the simulation deviating from the NMR structure.

\section{RESULTS}

\section{${ }^{13} \mathrm{C}\left\{{ }^{15} \mathrm{~N}\right\}$ REDOR NMR of PG-LCTA-1421 complex}

${ }^{13} \mathrm{C}\left\{{ }^{15} \mathrm{~N}\right\}$ REDOR spectra during $32.4 \mathrm{~ms}$ dipolar evolution for whole cells of $S$. aureus labeled with D-[1-13 C]Ala and L- $\left[3-{ }^{13} \mathrm{C}\right]$ Ala complexed with LCTA-1421 are shown in Figure 3. For $S$. aureus when grown in the presence of alaphosphin $(5 \mu \mathrm{g} / \mathrm{ml})$ the provisioned D-[1-13 C]Ala does not scrambling to L-[1- $\left.{ }^{13} \mathrm{C}\right] \mathrm{Ala} .{ }^{32}$ The ${ }^{13} \mathrm{C}$-carbonyl carbons of D$\left[1-{ }^{13} \mathrm{C}\right]$ Ala-D- $\left[1-{ }^{13} \mathrm{C}\right] \mathrm{Ala}$ appear at $175 \mathrm{ppm}(\mathrm{red})$, and the ${ }^{13} \mathrm{C}$-methyl carbon of L$\left[3-{ }^{13} \mathrm{C}\right]$ Ala at $30 \mathrm{ppm}$ (blue). The chemical shift assignments for the ${ }^{13} \mathrm{C}$-carbonyl carbons of D-[1- $\left.{ }^{13} \mathrm{C}\right]$ Ala-D-[ $\left[1-{ }^{13} \mathrm{C}\right]$ Ala were determined using ${ }^{13} \mathrm{C} \rightarrow{ }^{15} \mathrm{~N}$ transferred-echo doubleresonance NMR experiment of whole cells of $S$. aureus labeled with D-[1- $\left.{ }^{13} \mathrm{C}\right]$ Ala and $\left[{ }^{15} \mathrm{~N}\right] \mathrm{Gly} .{ }^{33}$ In the difference $(\Delta S)$ spectrum, both 175 - and 30-ppm peaks are dephased by the ${ }^{15} \mathrm{Ns}$ of LCTA-1421. An expanded region centered around $175 \mathrm{ppm}$ (Figure right) shows that the ${ }^{13} \mathrm{C}$-carbonyl carbon of $\mathrm{D}-\left[1-{ }^{13} \mathrm{C}\right]$ Ala are partially resolved. The 178 -ppm peak is assigned to carboxyl-carbonyl carbon and $173 \mathrm{ppm}$ is assigned to the peptidyl-carbonyl carbon of the D- $\left[1-{ }^{13} \mathrm{C}\right]$ Ala-D- $\left[1-{ }^{13} \mathrm{C}\right]$ Ala in the PG stem. ${ }^{33}$ The ${ }^{13} \mathrm{C}$-carbonyl carbons of D$\left[1-{ }^{13} \mathrm{C}\right]$ Ala-D- $\left[1-{ }^{13} \mathrm{C}\right] \mathrm{Ala}$ are dephased exclusively by the asparagine ${ }^{15} \mathrm{~N}$-amide of LCTA-142 due to its position found near to the bound D-Ala-D-Ala. ${ }^{9}$ The methyl carbon of $\mathrm{L}-\left[3-{ }^{13} \mathrm{C}\right] \mathrm{Ala}$, on the other hand, is exclusively dephased by the C-terminus ${ }^{15} \mathrm{~N}$-amide of LCTA-1421, based on earlier structural characterization of LCTA-1110 complexed to PG. ${ }^{15}$ LCTA-1110 is a fluorinated analogue of LCTA-1421 with a $p$-fluorophenylpiperazinamide at the C-terminus position (Figure 4, top).

Structural characterization of LCTA-1110 complexed to PG provided the first clue that the C-terminus of LCTA-1110 might be involved in binding to non-D-Ala-D-Ala segment of PG-stem structure, ${ }^{15}$ which led to the synthesis of LCTA-1421 to investigate the interaction. Figure 4 shows the ${ }^{13} \mathrm{~N}\left\{{ }^{19} \mathrm{~F}\right\}$ REDOR spectra of whole cells of $S$. aureus grown in defined media containing L- $\left[{ }^{15} \mathrm{~N}\right] \mathrm{Ala}$ (left) and L- $\left[\varepsilon_{-}{ }^{15} \mathrm{~N}\right] \mathrm{Lys}$ (right) complexed with LCTA-1110 (top) during $19.2 \mathrm{~ms}$ of dipolar evolution. ${ }^{15}$ The measured ${ }^{15} \mathrm{~N}-{ }^{19} \mathrm{~F}$ distance from the ${ }^{19} \mathrm{~F}$ of 
LCTA-1110 to the L- $\left[{ }^{15} \mathrm{~N}\right] \mathrm{Ala}$ of the bound PG was $6.0 \AA$, and the distance to the L$\left[\varepsilon-{ }^{15} \mathrm{~N}\right]$ Lys was $7.9 \AA .{ }^{15}$ REDOR distances unambiguously position the fluorine of LCTA-1110 away from the bound dipeptide D-Ala-D-Ala but near the L-Ala of the bound PG stem. Therefore, in PG-LCTA-1421 complex the methyl carbon of L- $\left[3-{ }^{13} \mathrm{C}\right]$ Ala in PG stem is dephased exclusively by the C-terminus ${ }^{15} \mathrm{~N}$-amide of LCTA-1421, positioning the C-terminus ${ }^{15} \mathrm{~N}$-amide in close vicinity to L-[3- $\left.{ }^{13} \mathrm{C}\right]$ Ala. The ${ }^{13} \mathrm{C}\left\{{ }^{15} \mathrm{~N}\right\}$ REDOR dephasing curve and the measured distances are shown in Figure 6.

\section{${ }^{15} \mathrm{~N}\left\{{ }^{13} \mathrm{C}\right\}$ REDOR NMR of PG-LCTA-1421 complex}

The positioning of the C-terminus ${ }^{15} \mathrm{~N}$-amide of LCTA-1421 in proximity of L-[3- $\left.{ }^{13} \mathrm{C}\right] \mathrm{Ala}$ is confirmed in Figure 5 which shows the ${ }^{15} \mathrm{~N}\left\{{ }^{13} \mathrm{C}\right\}$ REDOR spectra of whole cells of $S$. aureus grown in defined media containing D- $\left[1-{ }^{13} \mathrm{C}\right]$ Ala and $\mathrm{L}-\left[3-{ }^{13} \mathrm{C}\right]$ Ala complexed to LCTA-1421 during $16.2 \mathrm{~ms}$ dipolar evolution. The inset shows the partially resolved amide peaks of LCTA-1421. The 85-ppm peak is assigned to the ${ }^{15} \mathrm{~N}$-amide of the asparagine side chain, and the $92 \mathrm{ppm}$ to the $\mathrm{C}$-terminus ${ }^{15} \mathrm{~N}$-amide of LCTA-1421. In the $\Delta S$ spectrum, the C-terminus ${ }^{15} \mathrm{~N}$-amide at $92 \mathrm{ppm}$ is dephased by the ${ }^{13} \mathrm{C}$-methyl carbon of the L-[3-13 $\left.\mathrm{C}\right] \mathrm{Ala}$ and the 85 -ppm peak by the ${ }^{13} \mathrm{C}$-carbonyl carbons of the bound D-[1- $\left.{ }^{13} \mathrm{C}\right] \mathrm{Ala}-\mathrm{D}-\left[1-{ }^{13} \mathrm{C}\right] \mathrm{Ala}$.

\section{${ }^{13} \mathrm{C}-{ }^{15} \mathrm{~N}$ REDOR distance constraints for PG-LCTA-1421 complex}

The calculated ${ }^{13} \mathrm{C}\left\{{ }^{15} \mathrm{~N}\right\}$ REDOR dephasing curves for whole cells of $S$. aureus labeled with D-[1- $\left.{ }^{13} \mathrm{C}\right]$ Ala and L- $\left[3-{ }^{13} \mathrm{C}\right]$ Ala complexed with LCTA-1421 are shown in Figure 6 (left). The dephasing curve for the carboxyl D-[1- $\left.{ }^{13} \mathrm{C}\right] \mathrm{Ala}_{5}$ is shown in red solid line, and peptidylcarbonyl carbon of D-[1-13 $\mathrm{C}] \mathrm{Ala}_{4}$ is shown in red dotted line. Each calculated dephasing curve includes ${ }^{13} \mathrm{C}$-natural abundance contribution, which is fully dephased to $1 \%$ by $2 \mathrm{~ms}$. The calculated ${ }^{13} \mathrm{C}-{ }^{15} \mathrm{~N}$ distances for the Asn ${ }^{15} \mathrm{~N}$-amide of LCTA-1421 to the carboxyl- and peptidyl-carbonyl carbons of the bound $\mathrm{D}-\left[1-{ }^{13} \mathrm{C}\right] \mathrm{Ala}-\mathrm{D}-\left[1-{ }^{13} \mathrm{C}\right] \mathrm{Ala}$ are 4.8 and $5.1 \AA$, respectively. The ${ }^{13} \mathrm{C}-{ }^{15} \mathrm{~N}$ distance from the C-terminus ${ }^{15} \mathrm{~N}$-amide of LCTA-1421 to the alanyl-methyl carbon of L-[3-13 C]Ala (30 ppm) is $3.5 \AA$. This positions the ${ }^{15} \mathrm{~N}$-amide of the asparagine side chain in LCTA- 1421 to $3.5 \AA$ from the $\mathrm{L}-\left[3-{ }^{13} \mathrm{C}\right] \mathrm{Ala}$ and $\mathrm{C}$-terminus ${ }^{15} \mathrm{~N}$-amide to 5.1 and $4.8 \AA$ from the ${ }^{13} \mathrm{Cs}$ in bound dipeptide $\mathrm{D}-\left[1-{ }^{13} \mathrm{C}\right] \mathrm{Ala} 4-\mathrm{D}-\left[1-{ }^{13} \mathrm{C}\right] \mathrm{Ala} 5$, respectively.

Comparable ${ }^{13} \mathrm{C}-{ }^{15} \mathrm{~N}$ distances are determined from ${ }^{15} \mathrm{~N}\left\{{ }^{13} \mathrm{C}\right\}$ REDOR dephasing curves shown in Figure 6 (right). The red line is the calculated dephasing curve for the asparagine ${ }^{15} \mathrm{~N}$-amide dephasing (red circles) for two ${ }^{13} \mathrm{C}^{15} \mathrm{~N}$ distances of 4.3 and $5.5 \AA$. The blue line is the calculated dephasing curve for the C-terminus ${ }^{15} \mathrm{~N}$-amide of LCTA-1421 dephasing (blue circles) for the ${ }^{13} \mathrm{C}-{ }^{15} \mathrm{~N}$ distances of $3.8 \AA$. The ${ }^{13} \mathrm{C}-{ }^{15} \mathrm{~N}$ distances determined by ${ }^{15} \mathrm{~N}\left\{{ }^{13} \mathrm{C}\right\}$ REDOR are in reasonable agreement with ${ }^{13} \mathrm{C}\left\{{ }^{15} \mathrm{~N}\right\}$ REDOR results. The measured ${ }^{13} \mathrm{C}-{ }^{15} \mathrm{~N}$ distances are illustrated in Figure 6 (bottom) and are summarized in Supplementary Table S1. The measured REDOR distances are used as constraints for the molecular dynamic simulation of LCTA-1421 complexed to the PG-stem structure shown in Figure 6. 


\section{Antimicrobial activities of the carboxyl-terminus modified glycopeptide antibiotics}

Supplementary Table S2 shows the minimal inhibitory concentrations (MICs) of vancomycin, eremomycin, LCTA-1421, and LCTA-1110 against vancomycin-susceptible and resistant strains of Gram-positive bacteria. The C-terminus modified glycopeptides, LCTA-1421 and LCTA-1110, exhibit mild improved activities across-the-board against vancomycin-susceptible Gram-positives, vancomycin-intermediate resistant $S$. aureus, and vancomycin-resistant $E$. faecium and $E$. faecalis.

\section{DISCUSSION}

\section{LCTA-1421 asparagine side chain functions as a "flap"}

Structure-activity studies have shown that the asparagine is essential for the activities in Type I glycopeptides. ${ }^{2,11,22}$ Schäfer et al. ${ }^{34}$ proposed that the vancomycin asparagine side chain functions as a gate to regulate the ligand access to the binding cleft. In an "open" conformation in the x-ray crystal structure of an asymmetric vancomycin dimer, the asparagine side chain swung out of the binding cleft with an acetate ion occupying the DAla-D-Ala binding site. In a "closed" conformation, the asparagine side chain is swung into the binding cleft. ${ }^{34}$ An $x$-ray crystal structure of vancomycin bound to diacetyl-L-Lys-DAla-D-Ala (Figure 2 left) also showed that the asparagine side chain is swung out of the binding cleft to accommodate the ligand binding. Loll et al. ${ }^{35}$ proposed that the asparagine side chain functions as a "flap" in the absence of a ligand, acting as a ligand surrogate by occupying the binding site. The "flap" prevents the hydration of the ligand binding cavity which is energetically favorable as the water molecules placed within a highly polarized binding pocket are thought to be difficult to remove in order for the ligand to bind.

It is unclear how critical the "flap" is for the glycopeptide activity. As shown in Supplemental Figure S1, Types III, and IV, glycopeptides have aromatic residues at amino acids in positions 1 and 3 that are cross-linked by a phenolic-ether linkage. This ridged macrocylic ring structure is incompatible with the proposed "flap" function in vancomycin and furthermore, glycopeptide antibiotics of Types III and IV exhibit potent antimicrobial activities, even in the absence of the "flap," suggesting that asparagine's "flap" mechanism may not have a significant effect.

\section{LCTA-1421 asparagine side chain forms a binding cleft}

REDOR measurements position the asparagine ${ }^{15} \mathrm{~N}$-amide of LCTA-1421 at 5.1 and $4.8 \AA$ from the ${ }^{13} \mathrm{C}$-carbonyl carbons of D-[1-13 C]Ala-D- $\left[1-{ }^{13} \mathrm{C}\right]$ Ala of the bound PG stem (Figure 6). The proximity of the asparagine ${ }^{15} \mathrm{~N}$-amide to the binding cleft is contrary to the average $\mathrm{N}-\mathrm{C}$ distances of 7.9 and $6.1 \AA$ determined by x-ray diffraction on vancomycin's hexamerrepeat unit (PDB identifier 1FVM). Each individual $\mathrm{N}-\mathrm{C}$ distance in vancomycin's hexamer unit are tabulated and shown in Supplementary Table S3. In an X-ray crystal structure, the asparagine side chain of vancomycin is positioned out of the D-Ala-D-Ala binding site; in contrast, solid-state NMR positions the asparagine sidechain closer to the D-Ala-D-Ala binding pocket. We believe that the crystallization of vancomycin, forming a hexamer-repeat unit, affects the conformation of the vancomycin-dipeptide bound structure. In comparison, solution-state NMR of the chloroeremomycin dimer determines that the corresponding N-C 
distances are 6.9 and $4.4 \AA . .^{10}$ The solution-state NMR measurement agrees closely with REDOR NMR distance measurements of 5.1 and $4.8 \AA$ (Figure 6). However, one caveat is that the solution NMR structure represents a chloroeremomycin bound to a model peptide mimicking PG as a dimer. We have found that glycopeptide antibiotics that readily form a dimer in a solution, ${ }^{36-38}$ when complexed to whole cells of $S$. aureus, are found as a monomer when bound to PG. ${ }^{15,16,39}$ Even one of the most strongest dimer-forming glycopeptides, oritavancin, is found as a monomer when complexed to the PG in whole cells of $S$. aureus. ${ }^{16}$ Hence, distance constraints determined by REDOR NMR represent in vivo glycopeptide conformation of monomeric-PG binding in the cell wall of intact whole cells, without any effects from drug dimerization, PG-mimic binding, or crystal-lattice constraints.

We propose an alternative relationship between the asparagine side chain and the formation of the ligand-binding site. The asparagine side chain does not directly form a hydrogen bond with D-Ala-D-Ala, but its proximity to the bound dipeptide strongly suggests a possible interaction with the $N$-methyl-leucine ( $1^{\text {st }}$ amino acid of LCTA-1421). The asparagine side chain interaction with the $\mathrm{N}$-methyl-leucine can form a binding cavity that can stabilize the dipeptide binding. Either Edman degradation of the N-methyl-leucine in eremomycin (the parent compound of LCTA-1421), ${ }^{40}$ or the replacement of asparagine with glutamine or aspartate can disrupt this action, thus diminishing antimicrobial activities. In the case of asparagine substitution by isoaspartate, the D-Ala-D-Ala binding site is destroyed by rearrangement, forming CDP-I, which is devoid of antimicrobial activities. ${ }^{41}$ REDOR distance constraints indicate that the asparagine and leucine side chains constitute a part of a hydrophobic pocket necessary for the D-Ala-D-Ala binding. The proposed interaction between the asparagine and $\mathrm{N}$-methyl-leucine in the presence of dipeptide will require further investigation.

\section{Carboxyl-terminus of LCTA-1421 interacts with the non-D-Ala-D-Ala segments of PG}

The solid-state NMR measurements position the L-Ala segment of the bound PG-stem near the C-terminus of the LCTA-1421 (Figure 6). The measured ${ }^{13} \mathrm{C}-{ }^{15} \mathrm{~N}$ distance between the C-terminus ${ }^{15} \mathrm{~N}$-amide of LCTA-1421 and the L-[3-13 C]Ala of the PG stem is 3.5 A by ${ }^{13} \mathrm{C}\left\{{ }^{15} \mathrm{~N}\right\}$ REDOR (Figure 3) and $3.8 \AA$ by ${ }^{15} \mathrm{~N}\left\{{ }^{13} \mathrm{C}\right\}$ REDOR (Figure 5). The results are in excellent agreement with the position of fluorine in LCTA-1110 (Figure 4) bound to PG in intact whole cells of $S$. aureus determined at $6.0 \AA$ from the ${ }^{15} \mathrm{~N}$ of L- $\left[{ }^{15} \mathrm{~N}\right] \mathrm{Ala}$ of the bound PG stem. ${ }^{32}$ These structural measurements are consistent with the $\mathrm{C}$-terminus of glycopeptide interaction with the non-D-Ala-D-Ala segments of PG.

The MIC measurements (Table S2) show that the C-terminus modifications enhance the antimicrobial activities of glycopeptides. The MIC values of LCTA-1421 and LCTA-1110 are more active than the parent compound eremomycin. The reason for the enhanced activities is that the C-terminus modification enhances glycopeptide-PG binding through interactions that involves more than just D-Ala-D-Ala binding. REDOR distance constraints positions the C-terminus of LCTA-1421 in vicinity of the L-Ala of the bound PG-stem structure in intact whole cells of $S$. aureus. This non-D-Ala-D-Ala interaction is critical for enabling the drug binding to the D-Ala-D-Lac terminated PG stem found in vancomycinresistant enterococci, and thus is likely to be responsible for the small enhancement in 
activities of LCTA-1421 against vancomycin-resistant and intermediate resistant pathogens (Supplementary Table S2).

In conclusion, glycopeptide antibiotics exhibit potent antibacterial activities by inhibiting PG biosynthesis in Gram-positive bacteria. The primary glycopeptide-PG interaction involves the aglycon structure of glycopeptide binding to the D-Ala-D-Ala of PG-stem structure. However, structure activity relationship studies of chemically modified glycopeptides suggest that drug-target interaction is complex. In the case of C-terminus modified glycopeptides, the antibiotic C-terminus interactions with the non-D-Ala-D-Ala segments of PG improves drug activity. To investigate glycopeptides interactions with nonD-Ala-D-Ala segments of PG, we complexed LCTA-1421 to intact whole cells of $S$. aureus and we characterize the PG-LCTA-1421 complex using solid-state NMR. We have synthesized LCTA-1421 for this study with selective ${ }^{15} \mathrm{~N}$-isotope incorporations into its aglycon structure, one at the Asn sidechain and the other at the C-terminus. REDOR NMR measurements positioned the ${ }^{15} \mathrm{~N}$-amide of Asn sidechain of LCTA-1421 is in close proximity (5.1 and $4.8 \AA$ ) to the ${ }^{13} \mathrm{Cs}$ in bound D-[1-13 C]Ala-D-[1-13 C $]$ Ala dipeptide, which indicated that the asparagine plays an important role in D-Ala-D-Ala binding. We have also found that the C-terminus ${ }^{15} \mathrm{~N}$-amide of LCTA-1421 is positioned in close proximity to the $\mathrm{L}-\left[1-{ }^{13} \mathrm{C}\right] \mathrm{Ala}$ segment of the bound PG stem. Future experiments will be required to further investigate the glycopeptide C-terminus interactions with non-D-Ala-D-Ala segment of PGstem structure which is crucial for enhancing antimicrobial activity against the vancomycinresistant enterococci. Multiple REDOR distance constraints will be used to develop a detailed molecular model structure of glycopeptide-PG complex to provide structural insight for the development of novel therapeutic agents against emerging multi-drug resistant pathogens.

\section{Supplementary Material}

Refer to Web version on PubMed Central for supplementary material.

\section{Acknowledgments}

This paper is based on work supported by the National Institutes of Health under grant number GM116130.

The authors acknowledge Southern Methodist University's Center for Scientific Computation for computing resources, and thank Ms. Svetlana E. Solovieva and Ms. Elena P. Mirchink, D.Sc., (Gause Institute of New Antibiotics, Moscow) for the antibacterial activity of LCTA compounds.

\section{Abbreviations}

${ }^{13} \mathbf{C}\left\{{ }^{15} \mathbf{N}\right\}$ carbon channel observation with nitrogen dephasing

VRE vancomycin-resistant enterococci

VSE vancomycin-susceptible enterococci

HBPyU (benzotriazol-1-yloxy)dipyrrolidinocarbenium hexafluorophosphate

LCTA-1421 bis $\left[{ }^{15} \mathrm{~N}\right]$ amide-carboxyeremomycin 
LCTA-1110 eremomycin $p$-fluorophenylpiperazinamide

${ }^{15} \mathbf{N}\left\{{ }^{13} \mathbf{C}\right\}$ nitrogen channel observation with carbon dephasing

PG peptidoglycan

CPMAS cross-polarization at magic angle spinning

lipid II $\quad N$-acetylglucosamine- $N$-acetyl-muramyl-pentapeptide-pyrophosphorylundecaprenol

REDOR rotational-echo double resonance

PyBOP (benzotriazole-1-yloxy)tripyrrolidinophosphonium hexafluorophosphate

\section{References}

1. Goff D. Antimicrobial Efficacy Review. Infectious Disease Special Edition. 2002; 5:31-34.

2. Nagarajan, R. Glycopeptide Antibiotics. Vol. 63. Marcel Dekker; New York: 1994.

3. Nicolaou KC, Cho SY, Hughes R, Winssinger N, Smethurst C, Labischinski H, Endermann R. Solid- and solution-phase synthesis of vancomycin and vancomycin analogues with activity against vancomycin-resistant bacteria. Chemistry. 2001; 7:3798-3823. [PubMed: 11575782]

4. Loll PJ, Axelsen PH. The structural biology of molecular recognition by vancomycin [In Process Citation]. Annu Rev Biophys Biomol Struct. 2000; 29:265-289. [PubMed: 10940250]

5. Matsuhashi M, Dietrich CP, Strominger JL. Incorporation of glycine into the cell wall glycopeptide in Staphylococcus aureus: role of sRNA and lipid intermediates. Proc Natl Acad Sci USA. 1965; 54:587-594. [PubMed: 5218655]

6. Cegelski L, Kim SJ, Hing AW, Studelska DR, O’Connor RD, Mehta AK, Schaefer J. Rotationalecho double resonance characterization of the effects of vancomycin on cell wall synthesis in Staphylococcus aureus. Biochemistry. 2002; 41:13053-13058. [PubMed: 12390033]

7. Hammes WP, Neuhaus FC. On the mechanism of action of vancomycin: inhibition of peptidoglycan synthesis in Gaffkya homari. Antimicrobial Agents \& Chemotherapy. 1974; 6:722-728. [PubMed: 4451345]

8. Rao J, Colton IJ, Whitesides GM. Using Capillary Electrophoresis To Study the Electrostatic Interation Involved in the Association of D-Ala-D-Ala with Vancomycin. J Am Chem Soc. 1997; 119:9336-9340.

9. Nitanai Y, Kikuchi T, Kakoi K, Hanamaki S, Fujisawa I, Aoki K. Crystal structures of the complexes between vancomycin and cell-wall precursor analogs. J Mol Biol. 2009; 385:1422-1432. [PubMed: 18976660]

10. Prowse WG, Kline AD, Skelton MA, Loncharich RJ. Conformation of A82846B, a glycopeptide antibiotic, complexed with its cell wall fragment: an asymmetric homodimer determined using NMR spectroscopy. Biochemistry. 1995; 34:9632-9644. [PubMed: 7626632]

11. Nagarajan R. Structure-activity relationships of vancomycin-type glycopeptide antibiotics. J Antibiot. 1993; 46:1181-1195. [PubMed: 8407579]

12. Kim SJ, Singh M, Schaefer J. Oritavancin binds to isolated protoplast membranes but not intact protoplasts of Staphylococcus aureus. J Mol Biol. 2009; 391:414-425. [PubMed: 19538971]

13. Kim SJ, Schaefer J. Hydrophobic side-chain length determines activity and conformational heterogeneity of a vancomycin derivative bound to the cell wall of Staphylococcus aureus. Biochemistry. 2008; 47:10155-10161. [PubMed: 18759499]

14. Kim SJ, Matsuoka S, Patti GJ, Schaefer J. Vancomycin derivative with damaged D-Ala-D-Ala binding cleft binds to cross-linked peptidoglycan in the cell wall of Staphylococcus aureus. Biochemistry. 2008; 47:3822-3831. [PubMed: 18302341]

15. Kim SJ, Cegelski L, Preobrazhenskaya M, Schaefer J. Structures of Staphylococcus aureus cellwall complexes with vancomycin, eremomycin, and chloroeremomycin derivatives by ${ }^{13} \mathrm{C}\left\{{ }^{19} \mathrm{~F}\right\}$ 
and ${ }^{15} \mathrm{~N}\left\{{ }^{19} \mathrm{~F}\right\}$ rotational-echo double resonance. Biochemistry. 2006; 45:5235-5250. [PubMed: 16618112]

16. Kim SJ, Cegelski L, Studelska DR, O’Connor RD, Mehta AK, Schaefer J. Rotational-echo double resonance characterization of vancomycin binding sites in Staphylococcus aureus. Biochemistry. 2002; 41:6967-6977. [PubMed: 12033929]

17. Olsufyeva EN, Berdnikova TF, Miroshnikova OV, Reznikova MI, Preobrazhenskaya MN. Chemical modification of antibiotic eremomycin at the asparagine side chain. J Antibiot. 1999; 52:319-324. [PubMed: 10348049]

18. Cooper RD, Snyder NJ, Zweifel MJ, Staszak MA, Wilkie SC, Nicas TI, Mullen DL, Butler TF, Rodriguez MJ, Huff BE, Thompson RC. Reductive alkylation of glycopeptide antibiotics: synthesis and antibacterial activity. J Antibiot. 1996; 49:575-581. [PubMed: 8698642]

19. Nicas TI, Mullen DL, Flokowitsch JE, Preston DA, Snyder NJ, Zweifel MJ, Wilkie SC, Rodriguez MJ, Thompson RC, Cooper RD. Semisynthetic glycopeptide antibiotics derived from LY264826 active against vancomycin-resistant enterococci. Antimicrob Agents Chemother. 1996; 40:21942199. [PubMed: 8878606]

20. Malabarba A, Nicas TI, Thompson RC. Structural modifications of glycopeptide antibiotics. Med Res Rev. 1997; 17:69-137. [PubMed: 8979249]

21. Rodriguez MJ, Snyder NJ, Zweifel MJ, Wilkie SC, Stack DR, Cooper RD, Nicas TI, Mullen DL, Butler TF, Thompson RC. Novel glycopeptide antibiotics: N-alkylated derivatives active against vancomycin-resistant enterococci. J Antibiot. 1998; 51:560-569. [PubMed: 9711219]

22. Miroshnikova OV, Printsevskaya SS, Olsufyeva EN, Pavlov AY, Nilius A, Hensey-Rudloff D, Preobrazhenskaya MN. Structure-activity relationships in the series of eremomycin carboxamides. J Antibiot. 2000; 53:286-293. [PubMed: 10819300]

23. Gullion T, Schaefer J. Detection of weak heteronuclear dipolar coupling by rotational-echo doubleresonance nuclear magnetic resonance. Adv Magn Reson. 1989; 13:57-83.

24. Gullion T, Schaefer J. Rotational-echo double-resonance NMR. J Magn Reson. 1989; 81:196-200.

25. Solov'eva SE, Printsevskaya SS, Olsuf' eva EN, Batta G, Preobrazhenskaya MN. New derivatives of eremomycin containing ${ }^{15} \mathrm{~N}$ or $\mathrm{F}$ atoms for NMR study. Russian Journal of Bioorganic Chemistry. 2008; 34:747-754.

26. Kim, SJ., Preobrazhenskaya, M., Schaefer, J. Characterization of Staphylococcus aureus peptidoglycan tertiary structure using glycopeptides as probe by solid-state NMR. Interscience Conference on Antimicrobial Agents and Chemotherapy; Washington DC. 2008. p. F2-2073

27. Tong G, Pan Y, Dong H, Pryor R, Wilson GE, Schaefer J. Structure and dynamics of pentaglycyl bridges in the cell walls of Staphylococcus aureus by ${ }^{13} \mathrm{C}-{ }^{15} \mathrm{~N}$ REDOR NMR. Biochemistry. 1997; 36:9859-9866. [PubMed: 9245418]

28. Gullion T, Baker DB, Conradi MS. New, compensated Carr-Purcell sequences. J Magn Reson. 1990; 89:479-484.

29. Mueller KT, Jarvie TP, Aurentz DJ, Roberts BW. The REDOR transform: direct calculation of internuclear couplings from dipolar-dephasing NMR data. Chem Phys Lett. 1995; 242:535-542.

30. de la Caillerie, J-BdE, Fretigny, C. Analysis of the REDOR signal and inversion. J Magn Reson. 1998; 133:273-280. [PubMed: 9716468]

31. Vanommeslaeghe K, MacKerell AD Jr. Automation of the CHARMM General Force Field (CGenFF) I: bond perception and atom typing. J Chem Inf Model. 2012; 52:3144-3154. [PubMed: 23146088]

32. Kim SJ, Singh M, Preobrazhenskaya M, Schaefer J. Staphylococcus aureus peptidoglycan stem packing by rotational-echo double resonance NMR spectroscopy. Biochemistry. 2013; 52:36513659. [PubMed: 23617832]

33. Cegelski L, Steuber D, Mehta AK, Kulp DW, Axelsen PH, Schaefer J. Conformational and quantitative characterization of oritavancin-peptidoglycan complexes in whole cells of Staphylococcus aureus by in vivo ${ }^{13} \mathrm{C}$ and ${ }^{15} \mathrm{~N}$ labeling. J Mol Biol. 2006; 357:1253-1262. [PubMed: 16483598]

34. Schäfer M, Schneider TR, Sheldrick GM. Crystal structure of vancomycin. Structure. 1996; 4:1509-1515. [PubMed: 8994975] 
35. Loll PJ, Bevivino AE, Korty BD, Axelsen PH. Simultaneous recognition of a carboxylatecontaining ligand and an intramolecular aurrogate ligand in the crystal structure of an asymmetric vancomycin dimer. J Am Chem Soc. 1997; 119:1516-1522.

36. Sharman GJ, Try AC, Dancer RJ, Cho YR, Staroske T, Bardsley B, Maguire AJ, Cooper MA, O'Brien DP, Williams DH. The roles of dimerization and membrane anchoring in activity of glycopeptide antibiotics against vancomycin-resistant bacteria. J Am Chem Soc. 1997; 119:12041-12047.

37. Allen NE, LeTourneau DL, Hobbs JN Jr. The role of hydrophobic side chains as determinants of antibacterial activity of semisynthetic glycopeptide antibiotics. J Antibiot. 1997; 50:677-684. [PubMed: 9315081]

38. Beauregard DA, Williams DH, Gwynn MN, Knowles DJ. Dimerization and membrane anchors in extracellular targeting of vancomycin group antibiotics. Antimicrob Agents Chemother. 1995; 39:781-785. [PubMed: 7793894]

39. Kim SJ, Tanaka KS, Dietrich E, Rafai Far A, Schaefer J. Locations of the hydrophobic side chains of lipoglycopeptides bound to the peptidoglycan of Staphylococcus aureus. Biochemistry. 2013; 52:3405-3414. [PubMed: 23607653]

40. Printsevskaya SS, Pavlov AY, Olsufyeva EN, Mirchink EP, Isakova EB, Reznikova MI, Goldman RC, Branstrom AA, Baizman ER, Longley CB, Sztaricskai F, Batta G, Preobrazhenskaya MN. Synthesis and mode of action of hydrophobic derivatives of the glycopeptide antibiotic eremomycin and des-(N-methyl-D-leucyl)eremomycin against glycopeptide-sensitive and resistant bacteria. J Med Chem. 2002; 45:1340-1347. [PubMed: 11882003]

41. Harris CM, Kopecka H, Harris TM. The stabilization of vancomycin by peptidoglycan analogs. J Antibiot (Tokyo). 1985; 38:51-57. [PubMed: 3972728]

42. Nitanai, Y., Kakoi, K., Aoki, K. Protein Data Bank. 2000. Crystal Structure of the Complex between Vancomycin and a Cell wall Precursor Analog, Di-Acetyl-Lys-D-Ala-D-Ala. 


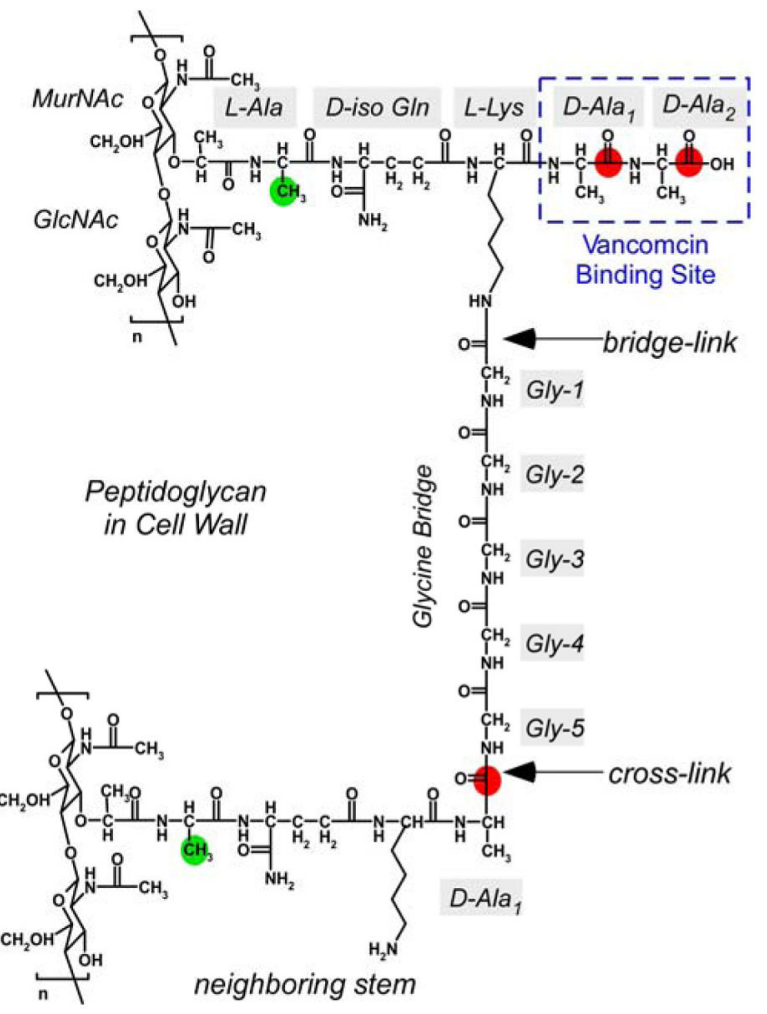

Figure 1.

Chemical structure of $S$. aureus cell wall peptidoglycan (PG). PG has a repeat unit consisting of a disaccharide (MurNAc-GlcNAc) and a pentapeptides stem consisting of the sequence L-Ala-D-iso-Gln-L-Lys-D-Ala-D-Ala. A pentaglycine bridge is attached to the $\varepsilon$ nitrogen of the L-Lys. The ${ }^{13} \mathrm{C}$-isotope enriched labels are incorporated into PG by growing $S$. aureus in the defined media containing D- $\left[1-{ }^{13} \mathrm{C}\right]$ Ala and $\mathrm{L}-\left[3-{ }^{13} \mathrm{C}\right] \mathrm{Ala}$, in the presence of the alanine racemase inhibitor alaphosphin $(5 \mu \mathrm{g} / \mathrm{ml})$. The positions of ${ }^{13} \mathrm{C}$-isotope enriched labels for the D- $\left[1-{ }^{13} \mathrm{C}\right] \mathrm{Ala}$ are shown as red circles, and $\mathrm{L}-\left[3-{ }^{13} \mathrm{C}\right] \mathrm{Ala}$ as green circles. The dotted blue box indicates the D-Ala-D-Ala terminus of the PG-stem, the known vancomycin binding site. 

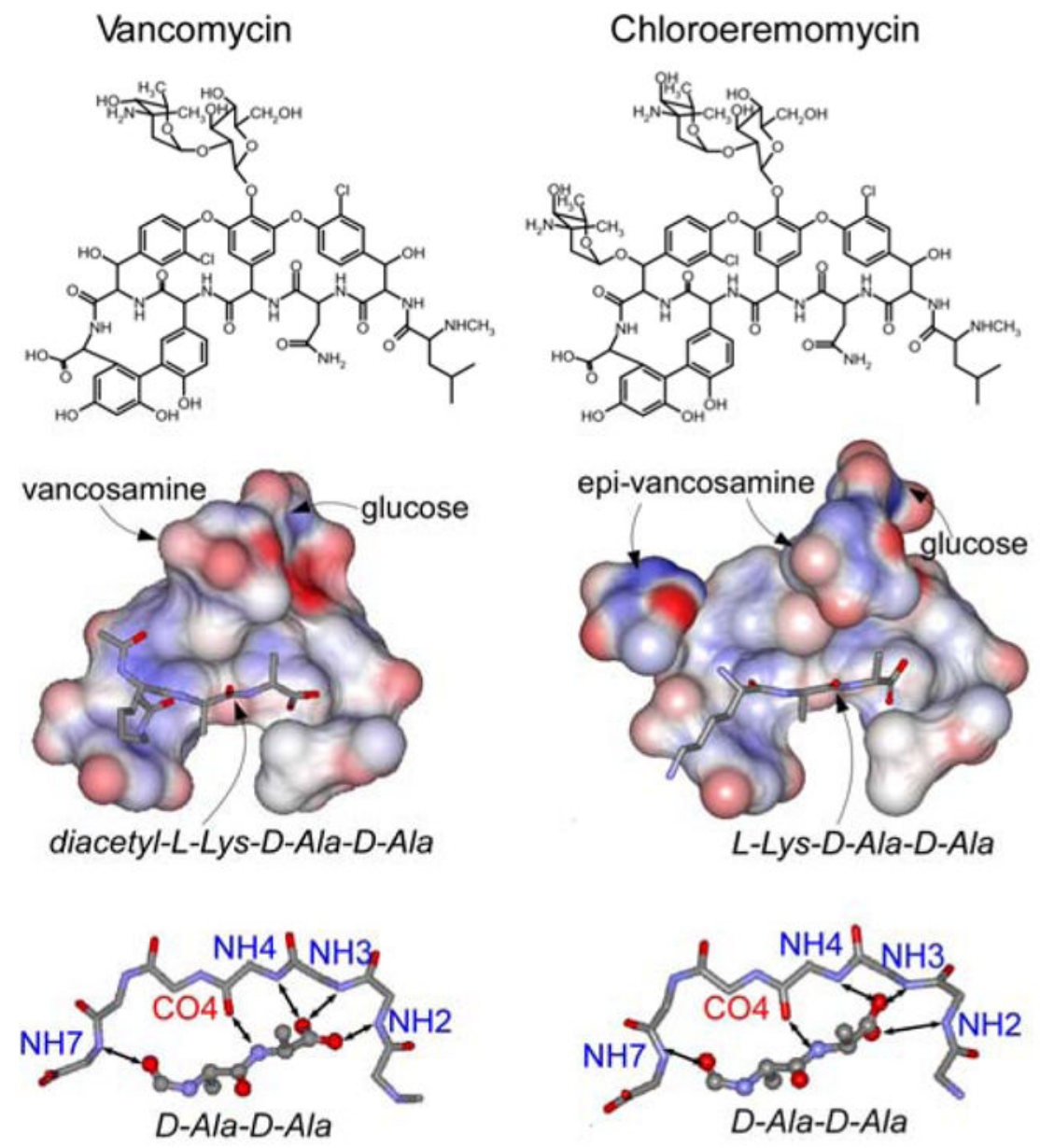

Figure 2.

Top: Chemical structures of Type I glycopeptides, vancomycin (left) and chloroeremomycin (right). The heptapeptide core is heavily cross-linked and modified by sugars. The disaccharide of vancomycin is glucose-vancosamine, and the disaccharide of eremomycin is glucose-4-epi-vancosamine. Middle: X-ray crystal structure of vancomycin (left) complexed with the diacetyl-L-Lys-D-Ala-D-Ala (PDB identifier 1FVM). ${ }^{42}$ A solution-state NMR structure of chloroeremomycin (right) complexed with L-Ala-D-iso-Glu-L-Lys-D-Ala-DAla (PDB identifier 1GAC). ${ }^{10}$ The L-Ala-D-iso-Glu of the bound ligand is omitted from the chloroeremomycin structure for clarity. Bottom: PG-stem binding involves formation of five hydrogen bonds connecting the heptapeptide backbone structures of vancomycin (left) and chloroeremomycin (right) to the dipeptide D-Ala-D-Ala. The glycopeptide backbones are labeled by the residue numbers and the hydrogen bonds are represented as arrows. The side chains of glycopeptides and D-Ala-D-Ala are omitted for clarity. 

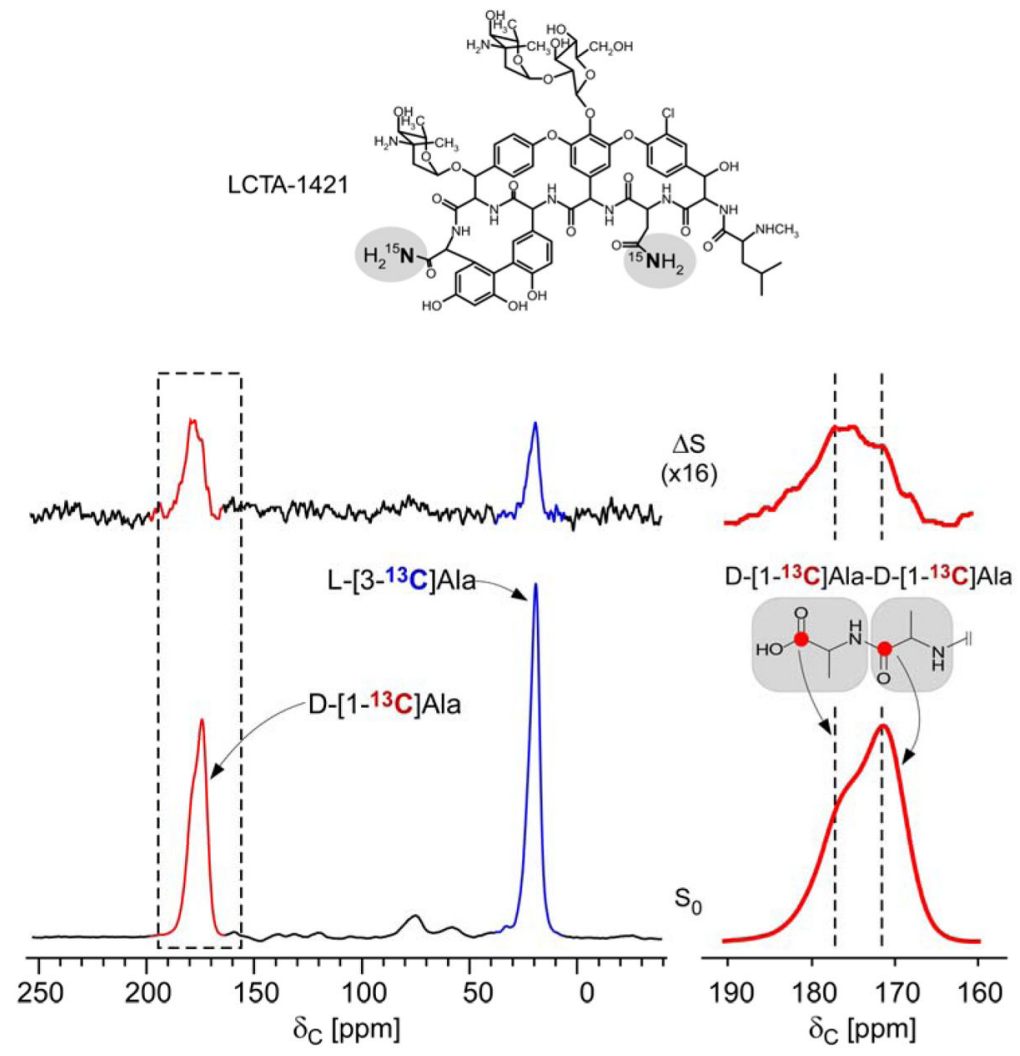

Figure 3.

Top: Chemical structure of LCTA-1421. LCTA-1421 has two ${ }^{15} \mathrm{~N}$-isotope enriched labels (gray circles): the first is a C-terminus ${ }^{15} \mathrm{~N}$-amide and the second is a ${ }^{15} \mathrm{~N}$-amide side chain of an asparagine. LCTA-1421 shows improved antimicrobial activity. Table S2 summarizes the minimum inhibitory concentrations of vancomycin, eremomycin, and C-terminusmodified eremomycins against vancomycin sensitive and resistant strains. Bottom: ${ }^{13} \mathrm{C}\left\{{ }^{15} \mathrm{~N}\right\}$ REDOR spectra during $32.4 \mathrm{~ms}$ dipolar evolution of whole cells of $S$. aureus grown in defined media containing D-[1- $\left.{ }^{13} \mathrm{C}\right]$ Ala and L- $\left[3-{ }^{13} \mathrm{C}\right]$ Ala complexed to LCTA-1421. Left: The alanyl-carbonyl carbon of D-[1-13 C]Ala is visible at $175 \mathrm{ppm}$ (red), and the alanyl-methyl carbon of L- $\left[3-{ }^{13} \mathrm{C}\right]$ Ala is visible at $30 \mathrm{ppm}$ (blue) in the reference spectra (bottom). In the difference $\Delta S$ spectra (top), only the carbons that are in dipolar contact with the ${ }^{15} \mathrm{~N}$ of LCTA-1421 are visible. Both the alanyl-carbonyl carbon of the D$\left[1-{ }^{13} \mathrm{C}\right] \mathrm{Ala}$ at $175 \mathrm{ppm}$ (red), and the alanyl-methyl carbon of the L-[3-13 C]Ala at $30 \mathrm{ppm}$ (blue) are dephased by the ${ }^{15} \mathrm{~N}$ of LCTA-1421. Right) The carbons of D-[1-13 C]Ala are resolved. The spectra were the result of the accumulation of 160,000 scans. 


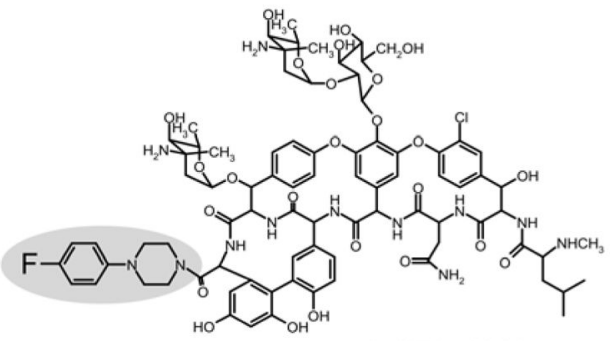

LCTA-1110

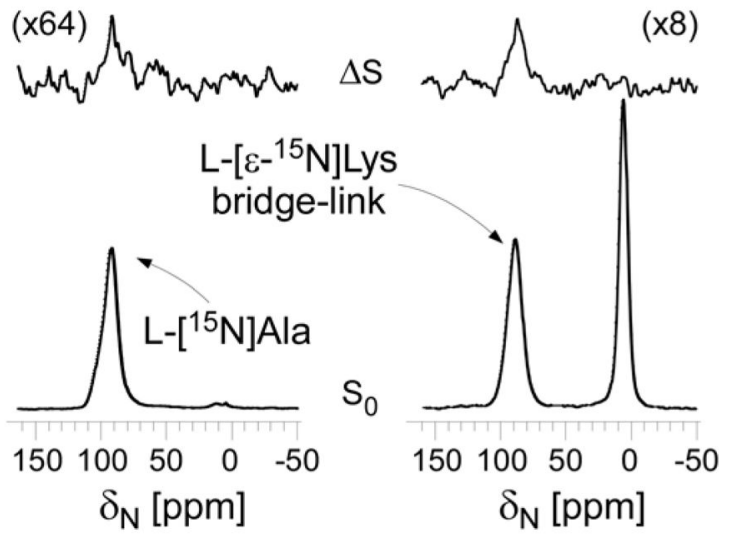

Figure 4.

${ }^{15} \mathrm{~N}\left\{{ }^{19} \mathrm{~F}\right\}$ REDOR spectra during $19.2 \mathrm{~ms}$ dipolar evolution of whole cells of $S$. aureus grown in defined media containing L- $\left[{ }^{15} \mathrm{~N}\right] \mathrm{Ala}$ (left) and L- $\left[\varepsilon-{ }^{15} \mathrm{~N}\right] \mathrm{Lys}$ (right) complexed with LCTA-1110 (top). The difference spectra $(\Delta S)$ are on the top and the full-echo spectra $\left(S_{O}\right)$ are on the bottom. For the ${ }^{15} \mathrm{~N}-{ }^{19} \mathrm{~F}$ distance from the L- $\left[{ }^{15} \mathrm{~N}\right]$ Ala of PG to the ${ }^{19} \mathrm{~F}$ of LCTA- 1110 is $6.0 \AA$, and the distance from the $\mathrm{L}-\left[\varepsilon^{-}{ }^{15} \mathrm{~N}\right] \mathrm{Lys}$ to the ${ }^{19} \mathrm{~F}$ of LCTA-1110 is $7.9 \AA .{ }^{15} \mathrm{~N}\left\{{ }^{19} \mathrm{~F}\right\}$ REDOR dephasing curve is found in Kim et al. ${ }^{15}$ 


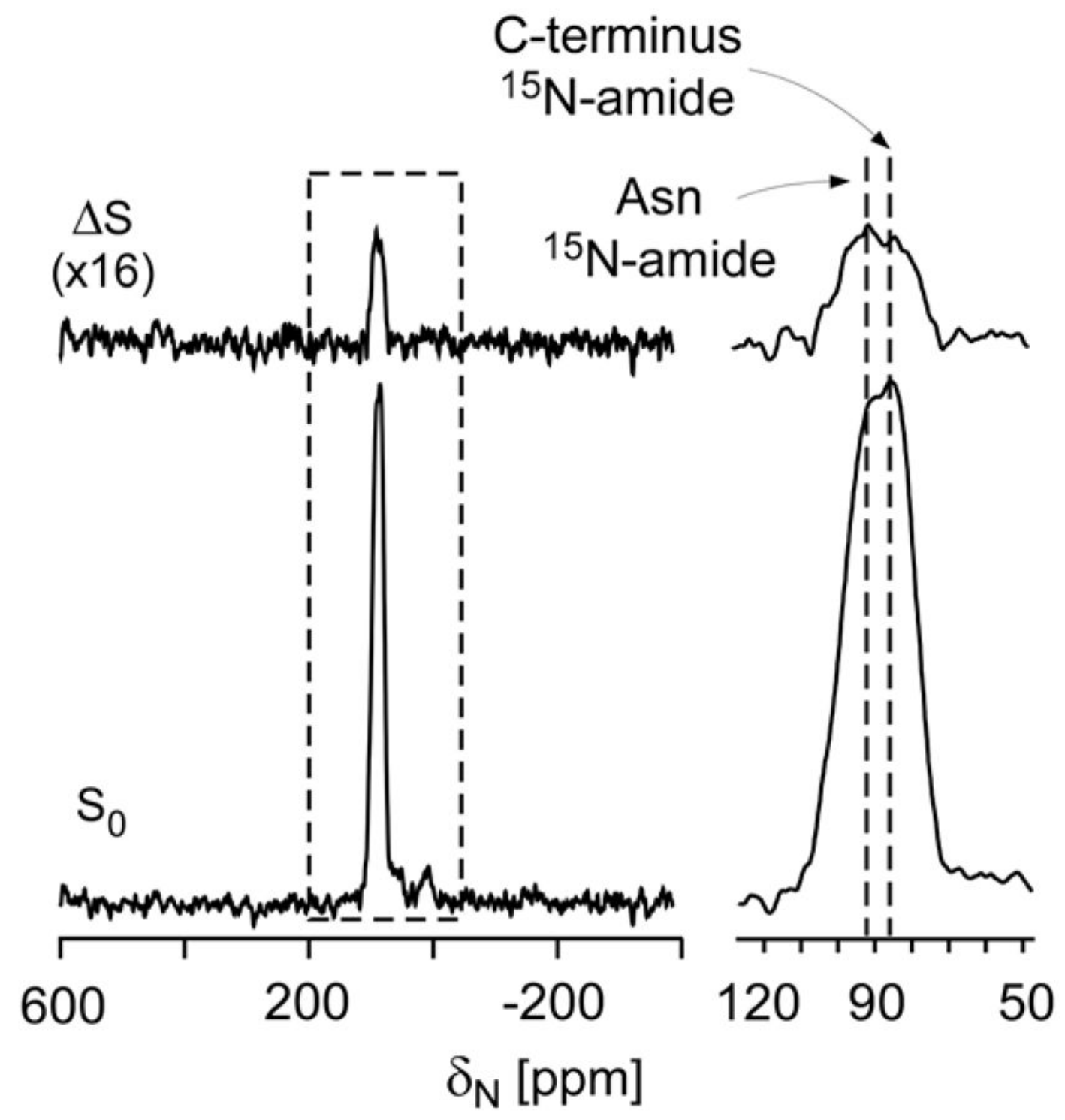

Figure 5.

${ }^{15} \mathrm{~N}\left\{{ }^{13} \mathrm{C}\right\}$ REDOR spectra during $16.2 \mathrm{~ms}$ dipolar evolution of whole cells of $S$. aureus grown in defined media containing D-[1- $\left.{ }^{13} \mathrm{C}\right]$ Ala and L- $\left[3-{ }^{13} \mathrm{C}\right]$ Ala complexed to LCTA-1421. The full echo spectrum $\left(S_{0}\right)$ is shown at the bottom of the figure and the REDOR difference $(\Delta S)$ is at the top. The amide regions of the full-echo and difference spectra are inset. The ${ }^{15} \mathrm{~N}$-amide of Asn in LCTA-1421 found at $92 \mathrm{ppm}$ is resolved from the ${ }^{15} \mathrm{~N}$-amide of $\mathrm{C}$-terminus amide at $85 \mathrm{ppm}$. The spectra were the result of the accumulation of 248,770 scans. 

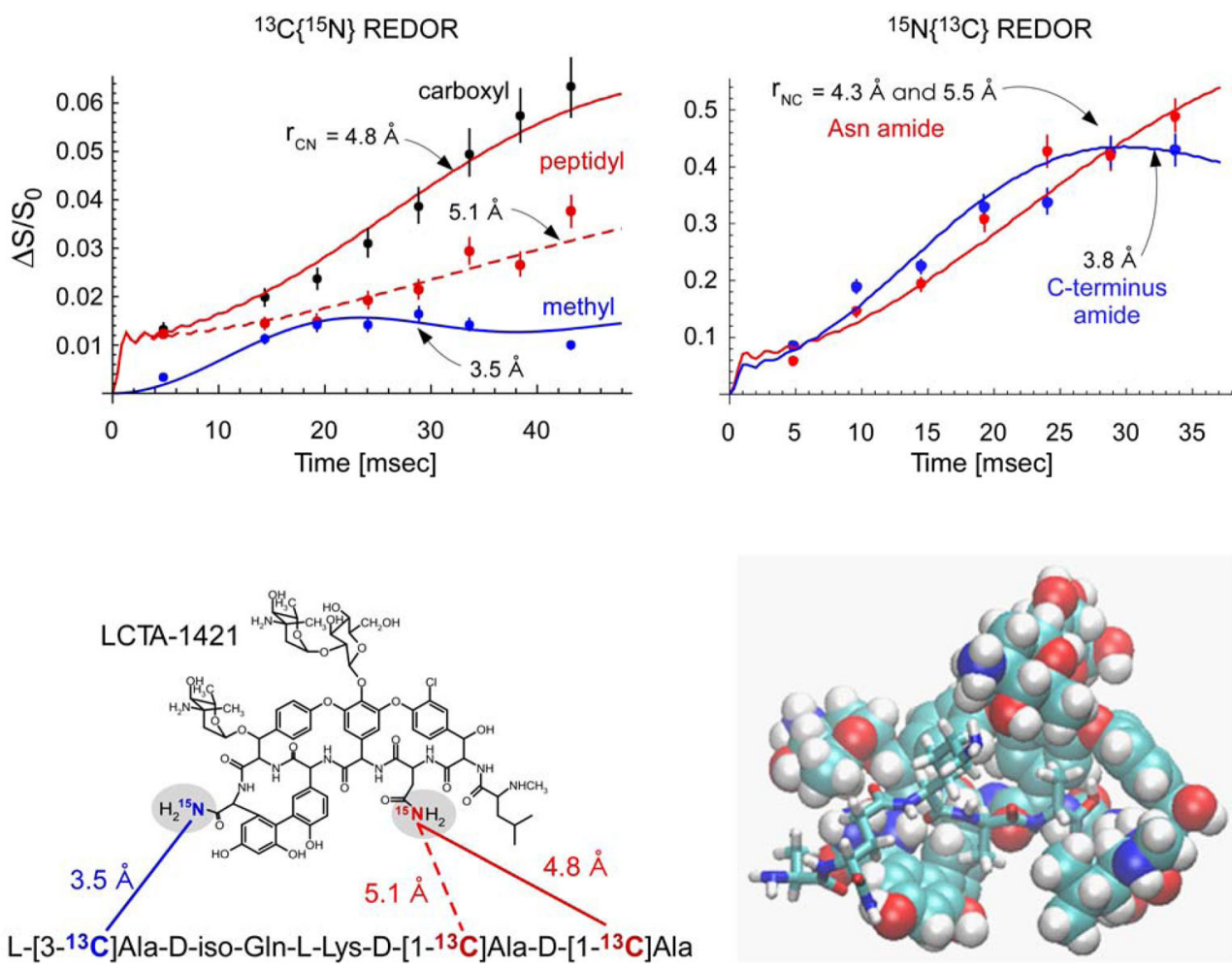

Figure 6.

Top Left: ${ }^{13} \mathrm{C}\left\{{ }^{15} \mathrm{~N}\right\}$ REDOR dephasing for whole cells of $S$. aureus grown in defined media containing D-[1-13 C]Ala and L- $\left[3-{ }^{13} \mathrm{C}\right]$ Ala complexed to LCTA-1421 plotted as a function of dipolar evolution. The calculated ${ }^{13} \mathrm{C}\left\{{ }^{15} \mathrm{~N}\right\}$ REDOR dephasing curves for $175 \mathrm{ppm}$ (solid red line), $173 \mathrm{ppm}$ (dotted red line), and $30 \mathrm{ppm}$ (solid blue line) correspond to the ${ }^{13} \mathrm{C}-{ }^{15} \mathrm{~N}$ distances of $5.1 \AA, 4.8 \AA$, and $3.5 \AA$, respectively. The ${ }^{13} \mathrm{C}\left\{{ }^{15} \mathrm{~N}\right\}$ REDOR dephasing curve is the result of the total accumulations of 475,396 scans for each $S_{O}$ and $S$ spectra. Top Right: ${ }^{15} \mathrm{~N}\left\{{ }^{13} \mathrm{C}\right\}$ REDOR dephasing are plotted as a function of dipolar evolution. The red line represents the calculated ${ }^{15} \mathrm{~N}\left\{{ }^{13} \mathrm{C}\right\}$ REDOR dephasing curve for the ${ }^{15} \mathrm{~N}-{ }^{13} \mathrm{C}$ distances of 4.3 and $5.5 \AA$, and the distances between the asparagine ${ }^{15} \mathrm{~N}$-amide side chain and the ${ }^{13} \mathrm{Cs}$ of D-[1- $\left.{ }^{13} \mathrm{C}\right]$ Ala-D- $\left[1-{ }^{13} \mathrm{C}\right]$ Ala bound to LCTA-1421. The blue line represents the dephasing curve for the ${ }^{15} \mathrm{~N}-{ }^{13} \mathrm{C}$ distance of $3.8 \AA$ between the C-terminus ${ }^{15} \mathrm{~N}$-amide of LCTA-1421 and the ${ }^{13} \mathrm{C}$ of $\mathrm{L}-\left[3-{ }^{13} \mathrm{C}\right] \mathrm{Ala}$ of PG. The ${ }^{15} \mathrm{~N}\left\{{ }^{13} \mathrm{C}\right\}$ REDOR dephasing curve is result of the total accumulations of 1,036,810 scans. Bottom Left: A summary of measured REDOR distance constraints. Bottom Right: A molecular dynamic simulation model structure of LCTA-1421 bound to a pentapeptide PG-stem structure (L-Ala-D-iso-Gln-L-Lys-D-Ala-DAla). The simulation was carried out without water molecules with the solid-state NMR distance constraints: i) $3.5 \AA$ between L[3-13 C]Ala with an ${ }^{15} \mathrm{~N}$-amide in C-terminus of LCTA-1421, ii) $5.1 \AA$ between $\mathrm{D}\left[1-{ }^{13} \mathrm{C}\right]$ Ala with ${ }^{15} \mathrm{~N}$-amide asparagine in LCTA-1421, and iii) $4.8 \AA$ between $\mathrm{D}\left[1-{ }^{13} \mathrm{C}\right] \mathrm{Ala}$ with the ${ }^{15} \mathrm{~N}$-amide at the C-terminus of LCTA-1421. REDOR NMR measurement of LCTA-1241 complex with whole cell $S$. aureus places the ${ }^{15} \mathrm{~N}$-amide side chain of asparagine approximately $5 \AA$ from the carbonyl-carbons of the 
bound D-Ala-D-Ala of PG. This is contrary to the position of the asparagine side chain found outside of the D-Ala-D-Ala binding pocket in x-ray crystal structures. 